\title{
Critique of "A Prospectively Studied Near- Death Experience with Corroborated Out-of-Body Perceptions and Unexplained Healing"
}

\author{
Michael J. Rush, M.A., P.G.Dip. \\ Alister Hardy Society for the Study of Spiritual Experience
}

\begin{abstract}
An article titled "A Prospectively Studied Near-Death Experience with Corroborated Out-of-Body Perceptions and Unexplained Healing" by Penny Sartori, Paul Badham, and Peter Fenwick was published in the Journal of NearDeath Studies in 2006. The authors concluded that the reported case strengthened "the cumulative experience derived from many other individual cases . . . that suggest that our current models of consciousness must expand in order to provide an adequate explanation of NDEs" (p. 83). However, a closer examination of Sartori et al.'s paper raises significant questions about their methodology and interpretation of their findings. In particular, certain methodological weakness and possible interpretation biases undermine the paper's conclusions. This critique addresses both Sartori et al.'s original paper and relevant parts of Sartori's (2008) Ph.D. thesis published subsequently.
\end{abstract}

KEY WORDS: near-death experience; critique; methodology; memory; expectation.

In 2006, Penny Sartori, Paul Badham, and Peter Fenwick published in the Journal of Near-Death Studies an article titled "A Prospectively Studied Near-Death Experience with Corroborated Out-of-Body Perceptions and Unexplained Healing." The article was based on Sartori's (2008) dissertation thesis study in which she investigated 10 research questions about near-death experiences (NDEs). However, Sartori et al.'s 2006 paper focused on one of the questions: whether the out-of-

\footnotetext{
Michael J. Rush, M.A., P.G.Dip., is Vice Chair of The Alister Hardy Society for the Study of Spiritual Experience in Lampeter, Wales. The opinions expressed in this article are those of the author alone. Correspondence regarding this article should be sent to Mike Rush at email: mikerush@virginmedia.com.
} 
body experience (OBE) in NDEs is veridical, that is, whether experiencers' reported perceptions are sometimes verified as having been accurate.

The authors began the article by reviewing some of the previous research on NDEs and representing their own study as having been a prospective, rather then retrospective, approach. Sartori et al. (2006) conducted the study where she worked as a nurse in the Intensive Therapy Unit (ITU) at Morriston Hospital, Swansea, Wales. The focus pertinent to the article was validation of the OBE aspect of the NDE by attempting to verify the experiencer's observations while in this state. The assumption usually made is that the near-death experiencer (NDEr) was clinically dead, or at least unconscious, at the time of the OBE. Sartori et al. attempted to gain veridical evidence by hiding brightly colored visual targets in the ITU out of normal range of sight, visible only from above. The authors described a case study of one of Sartori's patients and provided excerpts from his interview. They explored alternative explanations for his verified perceptions, including hypercarbia, analgesics, hallucination, and mental models, before concluding that his corroborated observations could be taken as validating the objective reality of his NDE. They also reported an unexplained healing in this patient after his NDE.

\section{Criticism of the Methodology}

I acknowledge some positive points about Sartori et al.'s (2006) methodological approach in this study. First, they used a mixed methodology that incorporated both quantitative and qualitative elements: They recorded statistical data on the incidence of NDEs and accompanying data on patients' blood chemistry, and they also conducted open-ended interviews to elicit data regarding NDErs' subjective experiences. Second, this study was prospective as opposed to many previous studies that were retrospective. Rather than relying on anecdotal accounts of observations made during NDEs, the researchers used pre-defined target symbols in an attempt to more convincingly assess accuracy of observation and thus avoid using retrospective anecdotes. Third, they drew blood samples during the patients' periods of unconsciousness, which enabled the authors to test some explanations of NDEs that invoke biochemical factors. Fourth, one of the observations the patient made during his NDE, the rather unique behavior of the physiotherapist repeatedly peeking nervously around a corner at the resuscitation 
process, seemed reasonably accurate. Fifth, the patient's condition had resulted in his experience of both hallucinations and an NDE, and he therefore was able to distinguish between the two. Finally, in her Ph.D. thesis, Sartori (2008, pp. 316-317) drew attention to the lack of understanding and support for patients who have had NDEs and who need to integrate the experience into their subsequent lives.

However, I also have a number of criticisms of the research methodology. To begin with, the reliability of accounts of anomalous experiences, including NDEs, have been challenged both on the basis of expectation (Katz, 1978; Lindbeck, 1984) and fallibility of memory (Blackmore, 1982; Neher, 1980). Some authors have countered regarding the role of expectation (Fox, 2005, p. 132; Greyson, 2000, p. 332) by citing accounts in which NDErs reported unexpected features of their experiences. However, this objection seems to be based on the assumption that such expectation is conscious and straightforward on the part of the NDEr. There is much empirical research that shows that experience can be influenced by an interacting collection of prior factors, both internal and external, of which an experiencer may be unaware. The concept of 'set and setting' in drug use research is well established (Delgarno \& Shewan, 2005; Hood, 2005, p. 354; Shewan, Delgarno, \& Reith, 2000). Walter Pahnke, who conducted the famous 'Good Friday' (Doblin, 1991) experiment commented:

\begin{abstract}
Psychological set is here defined as factors within the subject, such as personality, life history, expectation, preparation, mood prior to the session and, perhaps most important of all, the ability to trust, to let go, to be open to whatever comes. The setting is here defined as factors outside the individual, such as the physical environment in which the drug is taken, the psychological and emotional atmosphere to which the subject is exposed, how he is treated by those around him and what the experimenter expects the drug reaction to be. A person who has taken a psychedelic drug seems to be much more sensitive to non-verbal cues, perhaps because of an increase in suggestibility, but the exact role of suggestibility is a problem that needs to be further investigated. (Pahnke, 1967)
\end{abstract}

Researchers have highlighted that set and setting may also be important factors to consider in NDE research (Jansen, 1997). It has also been demonstrated that suggestion made without subjects' awareness can influence subjects' perceptions of subsequent events (Wiseman, Greening, \& Smith, 2003), often without subjects having any memory that the suggestion was made (Wiseman \& Greening, 2005).

Caroline Franks Davis (1989) recognized the problem of memory 
processing in relation to accounts of religious experiences, as did Mark Fox:

When we add to this sequence the recognition that memory is fluid, dynamic, and ongoing, and not just a static, fixed, once-for-all recollection of things past, we begin to see the very real potential that exists both for the construction of an extremely coherent and integrated story and why such a story should come to assume such vividness and detail. (Fox, 2003, p. 203)

That people's memories can be easily influenced by external sources has been thoroughly documented (Loftus, 2001, 2002, 2003b). Elizabeth Loftus commented that "leading questions could contaminate or distort a witness's memory" and that "misinformation can influence people's memories when they are interrogated in a suggestive fashion or when they talk to other people who give their version of events" (2003a, p. 868). Again, Fox recognized this possibility in the context of NDEs (2005, p. 199).

Finally, another cognitive mechanism that may be implicated in the construction of NDE testimony is cryptomnesia (Brédart, Lampinen, \& Defeldre, 2003; Brown \& Halliday, 1991), the phenomena of reproducing information under the mistaken belief that it is original. Kihlstrom (1987) reported that "implicit memory effects are conceptually similar to subliminal perception effects, in that both reveal the impact on experience, thought, and action of events that are not accessible to conscious awareness" (p. 1449). Pekala and Cardeña (2000) listed nine limitations and risks to take into account when assessing verbal reports of experiences: forgetting, reconstruction and confabulation, verbal description difficulties, distortion and substitution in observation, censorship, lack of independent verification, dissembling and social desirability, demand characteristics, and 'state-specific' memory. They cautioned that "investigators should remember that research is a social context in which they exert influences that they should be aware of and perhaps measure or control" (p. 56). In my view, Sartori et al.'s (2006) methodology did not control adequately for these cognitive mechanisms.

On another note, Sartori et al. (2006) reported that, prior to the patient interview, she gave him a description of her research in detail (p. 73). She did not provide the specific content of this description, so it is impossible to judge if the description may have subsequently influenced the patient's answers. Similarly, she conducted the study over a period of five years, and it seems unlikely that her research 
and interests remained completely secret during this time. Therefore, knowledge about the research could have influenced patients who subsequently had an NDE. This possibility would not rule out the apparently veridical observational evidence, but it could have influenced both patients' experience-due to implicit memory, suggestion, or subliminal processing-and subsequent accounts of their NDEs-due to fallibility of memory.

Sartori et al. (2006) did attempt to rule out the possibility that picture contents on the target cards could be guessed: They asked 50 staff and visitors to guess what was on a test set of cards and then excluded use of cards that were guessed correctly. The pictures that were used in the study featured scenes and advertisements (Sartori, 2008, p. 134). However, this pre-study activity may have leaked information about the research to the hospital staff. Even though the pictures on the cards actually used in the study were different, it isn't clear from Sartori's report how the test set of pictures differed from those used in the study. Any similarity could have provided a source of information leakage. To avoid this problem, the researchers could have used a completely independent control group to determine the probability of correct guesses due to chance.

Although only Sartori (2008) knew what pictures were on the cards, and she was the only person who moved them during cleaning of the ward, it is difficult to rule out the possibility that curious work colleagues could have peeked; previous researchers in a similar study had encountered this problem (Holden \& Joesten, 1990). Again, this possibility would provide a source of information leakage that could have affected patients' experiences and reports. This point seems speculative, but Sartori (2008) did report that the interviews about patients' NDEs were performed in ITU with the screens drawn (p. 139). Again, the possibility of staff and patients overhearing and subsequently being influenced is difficult to rule out.

Further criticism could be made of the interview technique. The transcript of Sartori's interview with the patient following his NDE and recovery betrays that she included several leading questions. For example, she asked, "Did you hear me say that I was going to clean your mouth?" (Sartori, 2006, p. 76) rather than "Did you hear me say anything?" Unsurprisingly, the patient then proceeded to describe Sartori doing something with his mouth. Additionally, she provided the patient with information during the interview that could have influenced his subsequent answers: 
PENNY: Do you recall hearing anything while in this state? PATIENT: Only the words that my father spoke, and the gentleman saying, "He isn't ready yet." Going back . . . I heard voices down below but couldn't make out what they were saying. Only thing ... something about my eye, life there. ... I don't know what he meant by that.

PENNY: I remember that. It was the consultant actually, and he looked in your eye and he shone a torch and he said, "Yes they are reacting, but unequal." (Sartori, 2006, p. 74)

Sartori did make some efforts to avoid suggestion. The patient information and consent form did not mention NDEs and did not reveal anything about the research by referring only to "unusual experiences" (Sartori, 2008, Appendix 1). Also, if patients had questions about the purpose of the research, Sartori answered them only after the interview was complete (p. 133). However, Sartori administered the NearDeath Experience Scale (Greyson, 1983) prior to the open-ended interview (p. 132), which may have primed experiencers' responses during the interviews. For research like this, in which the aim is verification of events, such information should have been given after the interview was complete, not before it. Sartori appears not to have asked one important question during the interview: Did the interviewee have any knowledge of the author's research and interests prior to his NDE? Sartori appears to have made this assumption, but it is not clear whether she checked it overtly. Regarding the patient in question, that he may have been aware of Sartori's focus could be inferred from his eagerness to report his NDE upon regaining consciousness. Even though the veracity of the patient's answer to this question depended on his honesty, an answer would have helped to defend against the criticisms discussed previously regarding expectation.

Another major problem with this-and other similar research, such as Ian Stevenson's (1966) and Erlendur Haraldsson's (2000) reincarnation studies-is that they hinge on the assessment of accuracy of a verbal report of a subjective experience. How is this accuracy measured? Drawing from earlier research of this type (Holden, 1988; Holden \& Joesten, 1990), Sartori et al. could have strengthened the methodology greatly by using a double-blind technique. The symbols could have been designed or chosen by someone having access to neither the patients nor the medical staff. The staff, including Sartori, would then have been ignorant of the targets, thus ruling out information leakage. Secondly, Sartori et al. could have employed a panel of 
people not otherwise associated with the study to judge the accuracy with which patients' reports corresponded to hospital records and to hidden targets. They could have scored accuracy of the reports individually to produce an averaged score. Although still problematic, this procedure would have helped to avoid experimenter bias in analysis of the results.

A more general methodological flaw is regarding the isolation of confounding factors. What is this method actually testing? Any 'hits' by patients in describing the hidden cards could potentially be taken as evidence, not for a veridical OBE, but for precognition or telepathy.

Finally, although Sartori et al. (2006) considered the patient's unexplained healing to have been a significant development, they did not assess the condition of his hand prior to his NDE. This aspect of the case should not, therefore, be included as evidence in a prospective study.

These criticisms may seem somewhat trite and pedantic, but I believe them to be justified considering that the phenomenon being tested is potentially paradigm shattering: Exceptional claims demand exceptional evidence.

\section{Criticism of the Results}

Regarding the results of the study, the primary issue is that, strictly speaking, it failed. Not one patient who reported an NDE also reported having observed the hidden cards. Therefore, I find it unclear how the authors have arrived at their conclusion, which may have been justified had the study been successful, solely on the basis of circumstantial observations. I would suggest that, whereas this case may add another retrospective report to the NDE data, it does not meet the prospective requirements of the study itself.

I found the presentation of the results also to be somewhat misleading. The transcripts of three separate interviews were concatenated into one account, giving the erroneous impression of a continuous narrative flow. Obviously it is impossible to publish full transcripts in a single journal article, but, to avoid confusion, Sartori et al. (2006) should have presented the excerpts unambiguously with their correct dates. This practice would have avoided researcher bias including a possible tendency to reconstruct evidence in a way that seemed to support their conclusions.

Also, the results seem to contain some internal inconsistencies. At first the patient clearly stated that he did not know what the nurse 
had put in his mouth (a catheter, then a pink sponge), but later he identified it without any doubt. The implication here is that Sartori revealed this information to him during the interview process; if this were the case, the patient's certainty would have been due to Sartori's revelation rather than to the patient's own perception.

\section{Criticism of the Discussion}

I found it difficult to agree with Sartori et al. (2006) where they used phrases such as "strong evidence," "many veridical elements," "extremely accurate account," "detailed events described," and "accurately reported the actions," phrases I do not think accurate considering the results they presented. I found only three veridical features listed in the report: a reference to an eye exam by the consultant, the nurse (Sartori) cleaning the patient's mouth, and the behavior of the physiotherapist.

The first and second of these features were actually reported inaccurately as revealed by the interview transcript. The consultant said, "Yes they are reacting, but unequal," not "something about my eye, life there" as the patient reported (Sartori et al., 2006, p. 74). Also, the patient was unable to identify the object that the nurse had in his mouth or what she was doing; only the color was correct. He initially described this object as "a long, pink lollipop" (p. 73), but according to Sartori et al., "he knew that his mouth was cleaned by using a pink sponge dipped in water" (p. 78). The patient had been in the ITU ward for some time and probably had a passing familiarity with its equipment and procedures. Among the large number of features the patient reported after his NDE, the majority were either not verified or were unverifiable. In fact, from the transcript the patient seemed more interested in the non-veridical aspects of his experience. This is an important point to which I will return later.

Considering that the challenge of ascertaining the timing of NDEs is critical to their explanation, that is, whether they occur during loss of consciousness, clinical death, unconsciousness, or on recovery, I found it problematic that the two estimates Sartori et al. (2006) provided of the patient's return to consciousness contradict each other. In the first instance he reportedly regained full consciousness three hours after the incident (p. 72), but in the second instance he reportedly recovered full consciousness four hours afterwards (p. 78).

Additionally, although the patient was reportedly unresponsive, he 
also reportedly displayed movement in his eyelids and limbs 30 minutes after he lost consciousness (Sartori et al., 2006, p. 72). Among the questions these data raised for me was the possibility that the patient was drifting in and out of consciousness or partly conscious for some of the time. Occasional or partial consciousness could easily explain his apparently veridical observation of the physiotherapist's behavior. From my own experience, in circumstances where one momentarily regains consciousness after being anesthetized, it is not easy to distinguish later whether the semi-waking interlude was real or imaginary. Crammer (2002) also reported this phenomenon from a first-person perspective when he entered a confused state and lost consciousness due to renal failure. He reported that "these arousals serve to show that, even in unconsciousness, auditory and visual stimuli flow in and are a reminder that they can stimulate without conscious perception" (p. 74). It is well recognized that anesthetically induced unconsciousness can involve different depths of awareness (Kihlstrom \& Cork, 2007). It would seem reasonable to assume that the same can be said for unconsciousness however it arises. Kihlstrom and Cork reported that "adequately anaesthetised patients can, indeed, show postoperative memory for unconsciously processed interoperative events" (p. 636). They proceeded to describe how "implicit perception," similar to that which operates in "blindsight," also seems to operate during unconsciousness (p. 638). The implications of these findings make it conceivable that Sartori's patient became aware of the physiotherapist's behavior through these mechanisms.

Finally, the movement of the patient's eyelids could suggest REM, which is associated with the dreaming state (Bunning \& Blanke, 2005; Dement \& Kleitman, 1957) and therefore raises the possibility that this was the point at which the patient constructed the NDE. Another possible point at which he could have generated the experience is when he was lifted back onto the bed. Bunning and Blanke (2005) report that "dynamic body position changes seem to influence the occurrence of OBEs" (p. 338).

It is not entirely clear what Sartori et al. (2006) considered significant about the apparently healed hand considering that their research project was an attempt to investigate whether or not consciousness can exist independently of the physical body. The patient also reportedly made a reference to the recovery of his kidneys after the NDE (p. 77); however, Sartori et al. clearly stated earlier in the article that his kidneys had recovered prior to the NDE (p. 71). Cases of spontane- 
ous healing are not uncommon, have a long history, and constitute a field of investigation in their own right (Ransom \& Alicke, 2012; Rose, 1954: Zanni \& Wick, 2005).

\section{Truth versus Meaning?}

The question of whether consciousness depends on the physical body is obviously important and demands further research. However, it is easy to overlook another important aspect in studies such as these: the meaning for, and effect of, the experience on the individual. As with other types of anomalous experiencers, NDErs may be wary of relating their experience to others. Sartori (2008) drew attention to this point: "Many of these NDErs had never told anyone or, in some cases, only very close members of family about the experience. This was because they did not fully understand it or they feared ridicule or disbelief" (p. 295).

However, many such NDErs are often glad to talk about their experience in a safe and supportive environment: "The patients who I did manage to follow-up were very grateful for the chance to discuss their experience again" (Sartori, 2008, p. 141). Sartori also pointed out that "from a nursing perspective, it is helpful for the NDEr to be given the opportunity to discuss the experience, thus helping them to integrate it into their life, giving them a greater understanding of their NDE which may otherwise take many months" (p. 317). However, she also noted an apparent lack of appreciation of the importance of NDEs amongst the majority of healthcare staff: "Very often healthcare professionals do not understand the experience, and the often dismissal of the experience as a side effect of drugs given is unhelpful" (p. 316). Perhaps it is the NDE's experiential value, rather than its evidential value, that is more important.

\section{Conclusion}

In summary, I found too many methodological problems with this study to accept the conclusions with much confidence. Verification of the out-of-body component failed, and the circumstantial evidence provided is either inaccurate or can be explained by known psychological processes. Most of the criticisms concern the influencing of NDErs' experience and descriptions and the accuracy of assessing verbal accounts. These problems may have been alleviated somewhat by an at- 
tempt to include a double-blind protocol, which is commonly used in many scientific and parapsychological studies. Also, although Sartori et al. (2006) went some way towards ruling out biochemical explanations in this particular case, it should be considered that NDEs are probably complex multi-factor phenomena and are unlikely to have a single explanatory mechanism. Although this study cannot realistically justify the conclusion that an expanded model of consciousness is required to explain NDEs, it does help draw attention to the importance of such experiences in clinical and healthcare contexts.

\section{References}

Blackmore, S. (1982). Beyond the body: An investigation of out-of-the-body experiences. London, England: William Heinneman.

Brédart, S., Lampinen, J. M., \& Defeldre, A. (2003). Phenomenal characteristics of cryptomnesia. Memory, 11(1), 1-11.

Brown, A., \& Halliday, H. (1991). Cryptomnesia and source memory difficulties, American Journal of Psychology, 104(4), 475-490.

Bunning, S., \& Blanke, O. (2005). The out-of body experience: Precipitating factors and neural correlates. Progress in Brain Research, 150, 331-350.

Crammer, J. L. (2002). Subjective experience of a confusional state. British Journal of Psychiatry, 180, 71-75.

Dalgarno, P., \& Shewan, D. (2005). Reducing the risks of drug use: The case for set and setting. Addiction Research and Theory, 13(3), 259-265.

Davis, C. F. (1989). The evidential force of religious experience. Oxford, England: Clarendon Press.

Dement, W., \& Kleitman, N. (1957). Sleep and dreams-The relation of eye movements during sleep to dream activity: An objective method for the study of dreaming, Journal of Experimental Psychology, 53(5), 339-46.

Doblin, R. (1991). Pahnke's "Good Friday experiment”: A long-term follow-up and methodological critique. Journal of Transpersonal Psychology, 23(1), 1-28.

Fox, M. (2003). Religion, spirituality and the near-death experience. London, England: Routledge.

Greyson, B. (1983). The near-death experience scale. Construction, reliability, and validity. Journal of Nervous and Mental Disease, 171(6), 369-375.

Greyson, B. (2000). Near-death experiences. In E. Cardeña, S. J. Lynn, \& S. Krippner (Eds.), Varieties of anomalous experience: Examining the scientific evidence (pp. 315-352). Washington, DC: American Psychological Association.

Haraldsson, E. (2000), Birthmarks and claims of previous-life memories I: The case of Purnima Ekanayake. Journal of the Society for Psychical Research, 64.1(858), 16-25.

Holden, J. M., \& Joesten, L. (1990). Near-death veridicality research in the hospital setting. Journal of Near-Death Studies, 9(1), 45-54.

Hood, R. (2005). Mystical, spiritual, and religious experiences. In R. F. Paloutzian \& C. L. Park (Eds.), Handbook of the psychology of religion and spirituality (pp. 348-363). New York, NY: Guilford Press. 
Jansen, K. (1997). The ketamine model of the near-death experience: A central role for the n-methyl-d-aspartate receptor. Journal of Near-Death Studies, $16(1), 5-26$.

Katz, S. (1978). Language, epistemology, and mysticism. In Steve Katz (Ed.), Mysticism and philosophical analysis (pp. 22-74). Oxford, England: Oxford University Press.

Kihlstrom, J. F. (1987). The cognitive unconscious, Science, 237(4821), 14451452.

Kihlstrom, J. F., \& Cork, R. C. (2007). Consciousness and anesthesia. In M. Velmans \& S. Schneider (Eds.), Blackwell companion to consciousness (pp. 628639). Oxford, England: Blackwell.

Lindbeck, G. (1984). The nature of doctrine: Religion and theology in a postliberal age. Philadelphia, PA: Westminster Press.

Loftus, E. (2001). Imagining the past. Psychologist, 14(11), 584-587.

Loftus, E. (2002, Summer). Memory faults and fixes. Issues in Science and Technology. 41-50.

Loftus, E. (2003a). Make-believe memories, American Psychologist, 58(11), 864-873.

Loftus, E. (2003b). Our changeable memories: Legal and practical implications. Nature Reviews Neuroscience, 4, 231-234.

Neher, A. (1980). The psychology of transcendence. London, England: PrenticeHall.

Pahnke, W. (1967). LSD and religious experience. In R. C. DeBold \& R. C. Leaf (Eds.), LSD, Man \& Society. Middletown, CT: Wesleyan University Press.

Pekala, R. J., \& Cardeña, E. (2000) Methodological issues in the study of altered states of consciousness and anomalous experiences. In E. Cardeña, S. J. Lynn, \& S. Krippner (Eds.), Varieties of anomalous experience: Examining the scientific evidence (pp. 47-82). Washington, DC: American Psychological Association.

Ransom, M. R., \& Alicke, M. D. (2012). It's a miracle: Separating the miraculous from the mundane. Archive for the Psychology of Religion, 34(2), 243-275.

Rose, L. (1954). Some aspects of paranormal healing, British Medical Journal, 2(4900), 1329-1332.

Sartori, P., Badham, P., \& Fenwick, P. (2006). A prospectively studied neardeath experience with corroborated out-of-body perceptions and unexplained healing, Journal of Near-Death Studies, 25(2), 69-84.

Sartori, P. (2008). The NDEs of hospitalized intensive care patients: A five year clinical study. Lampeter, Wales: Edwin Mellen Press.

Shewan, D., Dalgarno, P., \& Reith, G. (2000). Perceived risk and risk reduction among ecstasy users: The role of drug, set, and setting. International Journal of Drug Policy, 10(6), 431-453.

Stevenson, I. (1966). Twenty cases suggestive of reincarnation. New York, NY: American Society for Psychical Research.

Wiseman, R., Greening, E., \& Smith, M. (2003). Belief in the paranormal and suggestion in the séance room. British Journal of Psychology, 94(3), 285-297.

Wiseman, R., \& Greening, E. (2005). 'It's still bending': Verbal suggestion and alleged psychokinetic ability. British Journal of Psychology, 96, 115-127.

Zanni, G. R., \& Wick, J. Y. (2005). Physiological and psychological factors may be involved in remarkable recovery. Consultant Pharmacist, 20(8), 634-6, 638, $644-9$. 